\title{
RETROFITTING THE STRUCTURE OF THE CATALYTIC CRACKING REACTOR, FROM PETROBRAZI REFINERY, PLOIESTI BY TRANSFORMING THE STEEL STRUCTURE INTO A MOMENT RESISTING FRAME AND ENHANCING THE DAMPING OF THE STRUCTURE BY MEANS OF VISCOUS DAMPERS
}

\author{
IONUȚ VASILESCU - Eng., Technical Dir., Popp \& Asociații Consulting Engineers, email: ionut.vasilescu@p-a.ro, \\ EMIL TĂNASE - Eng., Popp \& Asociații Consulting Engineers, emil.tanase@p-a.ro \\ DRAGOȘ MARCU - Eng., General Manager, Popp \& Asociații, dragos.marcu@p-a.ro
}

\begin{abstract}
The present paper presents the structural and seismic retrofit solution for the structure of the Catalytic Cracking Reactor, from Petrobrazi Refinery, Ploiești, Romania. The spatial truss type steel structure was designed and built during 1965-1968, following United States codes of that time. The capacity of the reactor is intended to be increased, thus its weight increases by approx. $43 \%$. The retrofit solution had to take into consideration many criteria, not only technical, but also technological. After analyzing several possibilities, it was decided that the only feasible solution in order to fulfill all these requirements was to significantly increase the viscous damping of the structure - by introducing viscous dampers in its diagonals, accompanied by the strengthening of steel structure and changing the structural system into a moment resisting frame.
\end{abstract}

Keyword: retrofit, damping, energy dissipation, Fluid viscous damper (FVD)

\section{Introduction}

In Prahova County, within Petrobrazi Refinery, there is a Catalytic Cracking unit, which includes a Catalytic Cracking Reactor.

The unit comprises three main technological pieces of equipment: Reactor, Regenerator and Distillation Column.

The owner of the Refinery intended to technologically modernize this unit by modifying the Reactor, respectively by increasing its capacity and implicitly its mass and volume.

Since this is a structure built and commissioned about 40 years ago, that was designed and executed according to methods and standards which were modified significantly in these 40 years and which are currently obsolete - in terms of operational safety, it was compulsory to carry out a technical valuation to determine if and under what circumstances the desired modifications can be made. The retrofitting project took into account the Technical Valuation carried out by Dr. Eng. Traian Popp.

It should be mentioned that the structure already underwent a retrofitting process in 2000 that, after extensive analyses, consisted of a structural system involving energy dissipation provided by the damping with a tuned mass located in the upper part of the construction.

It is interesting that, even from 2000, the calculation showed that the best solution is the introduction of supplementary damping in the construction.

Then and now, 14 years apart the 2000 retrofitting, with the new request to increase the capacity of the reactor, the systematic calculation pointed out once again that the best solution to solve the issue is the same, respectively to introduce an overall supplementary damping in the construction. 


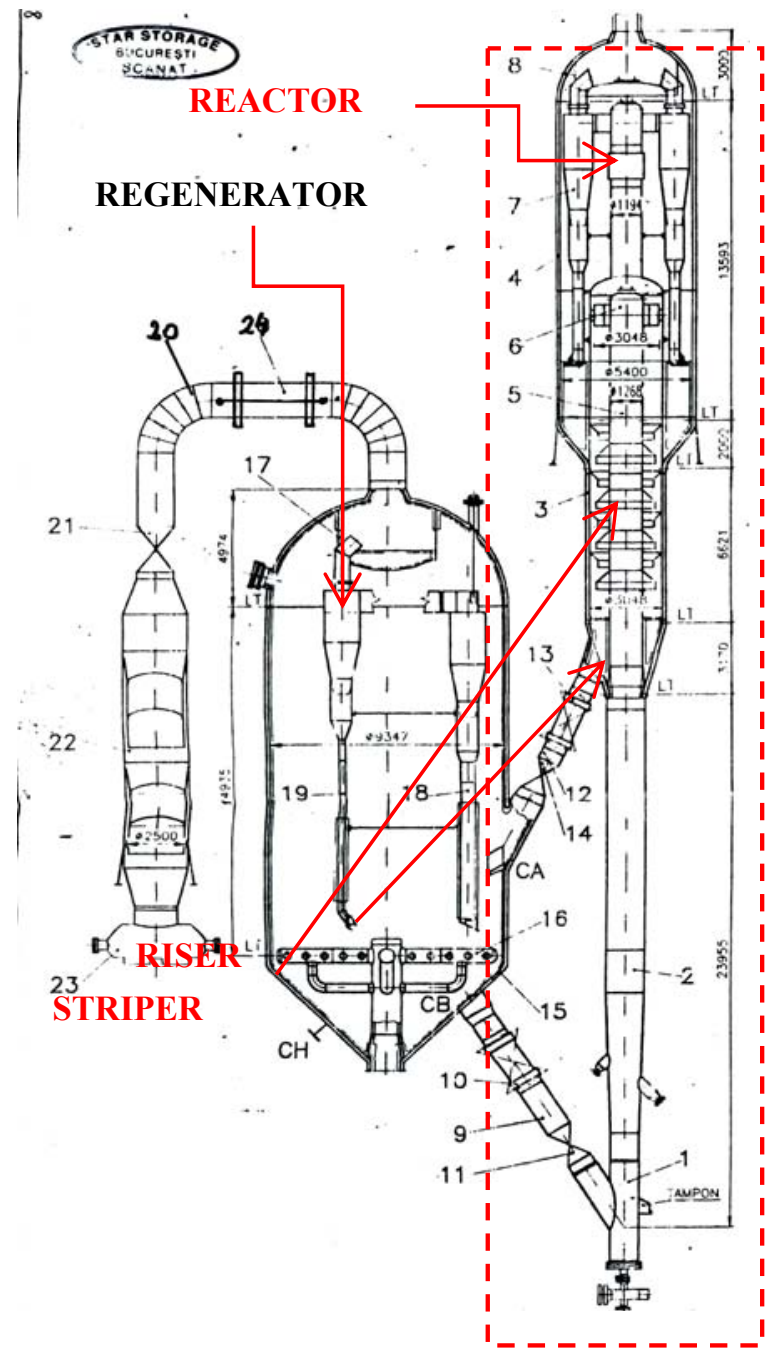

In 2011 and 2012, two other technical valuations were documented aiming to point out the possibility to enhance the capacity of the reactor by 83 , respectively 13 tons.

Comment: Since the space of one article does not allow the presentation of all aspects and issues, this article will refer mainly to the seismic analysis of the structure above the embedding elevation. The wind is also a significant action for the mentioned structure, at least in terms of displacements, but the behavior of the structure to the action of wind will be presented in a future article. Moreover, in this article we will not detail the intervention solutions at the level of the foundations. These were minimal (both from a technical point of view and in terms of costs), because the retrofit solution of the superstructure resulted in small exceedances of the resistance capacity of the foundations and of the base of the columns. The results of the analyses and the impact of the various retrofit solutions considered for the foundations will be revealed in a future article. Also, the technological stages to strengthen the steel structure may be the subject of a future article.

\section{Presentation existing structure}
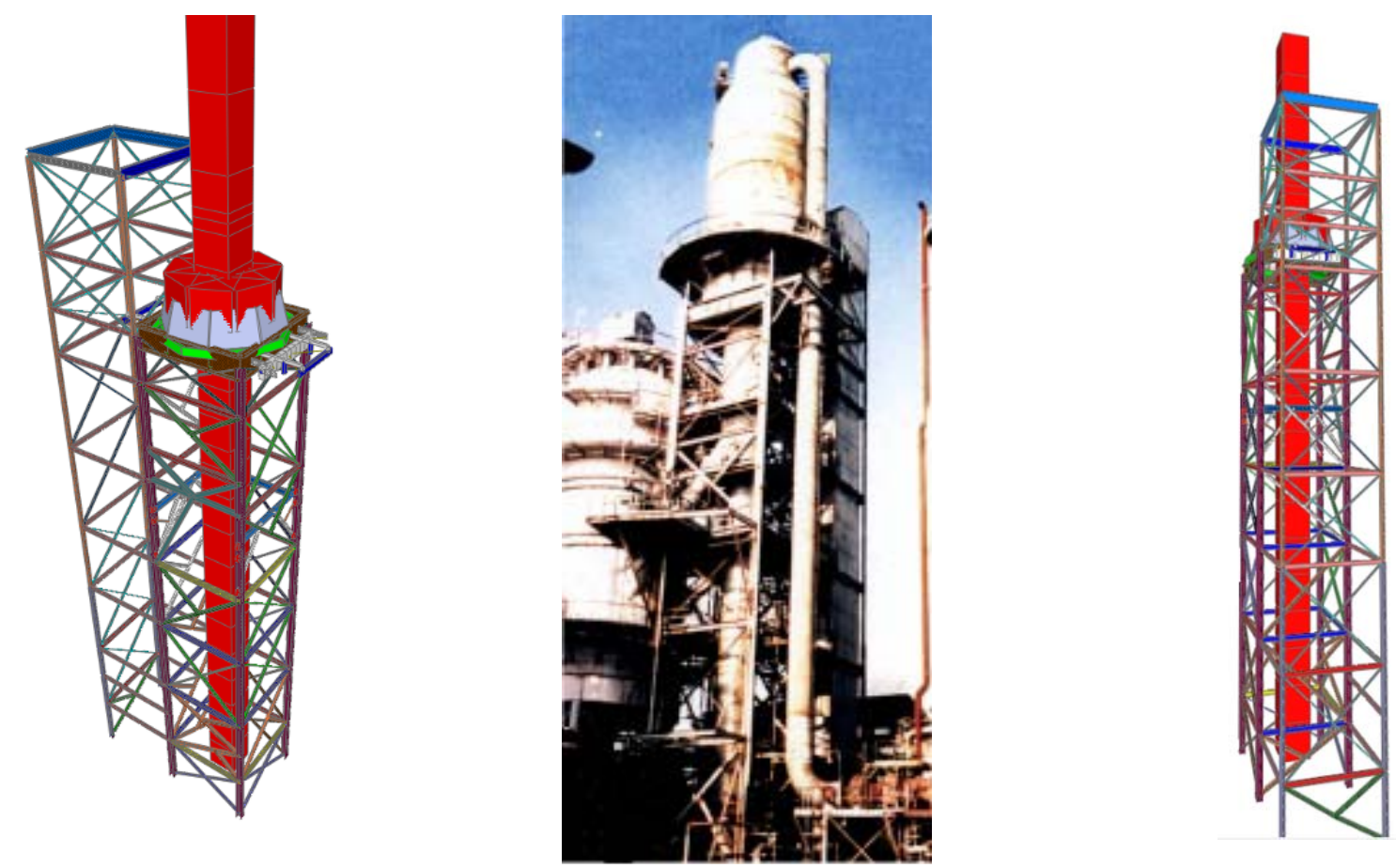

Fig. 1 - Existing structure on site and structural model 


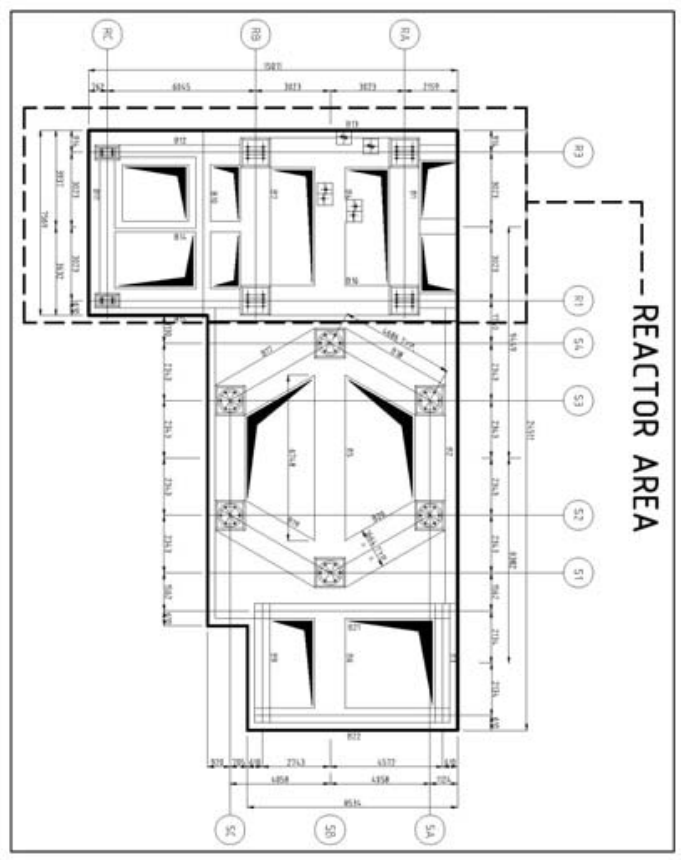

Fig.2 - Foundation plan Reactor + Regenerator + Striper

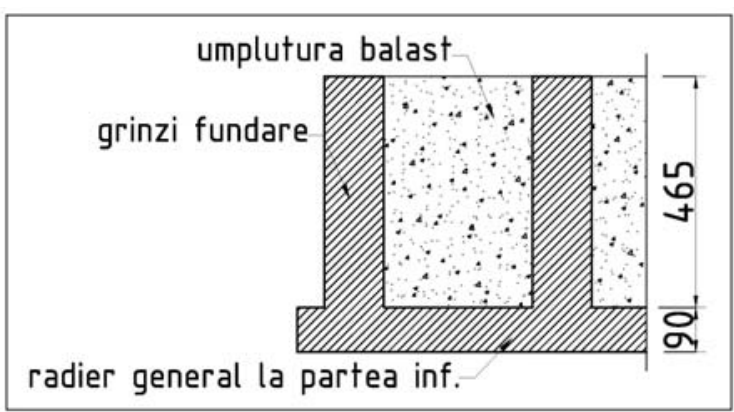

Fig. 3

The general foundation frame has a $90 \mathrm{~cm}$ thickness, and the inverted beams have a total height of $554 \mathrm{~cm}$; there is ballast filling between the beams.

The columns of the steel resistance structure are made of "H" profile and rests at the intersection of foundation frame beams, and the enforcement of the bases of the columns are done with 8 M68 anchor bolts; the bases of the columns, including the anchor bolts are embedded in concrete shells.

The steel structural elements are casted to ensure fire protection up to elevation $+10 \mathrm{~m}$ as compared to the base (on the first two levels), according to the norms and regulations of the Refinery.

The initial technological and constructive assembly was designed and executed in the US, in the ' 60 s.

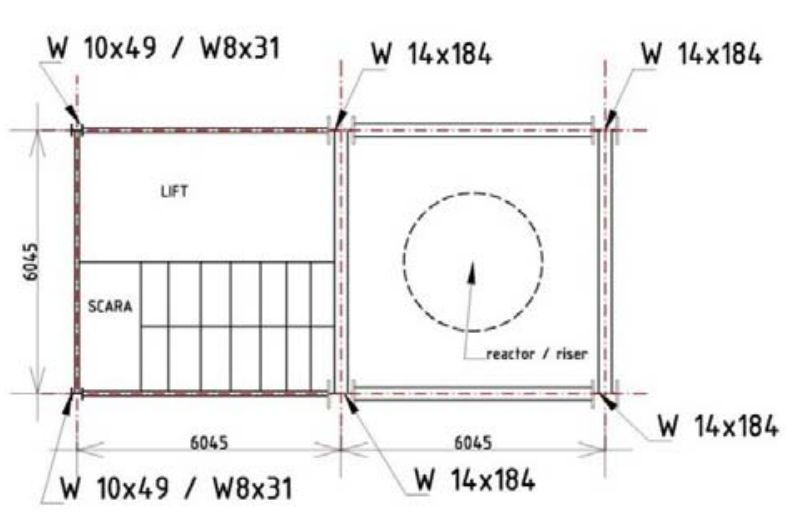

Fig. 4 - Structure Plan

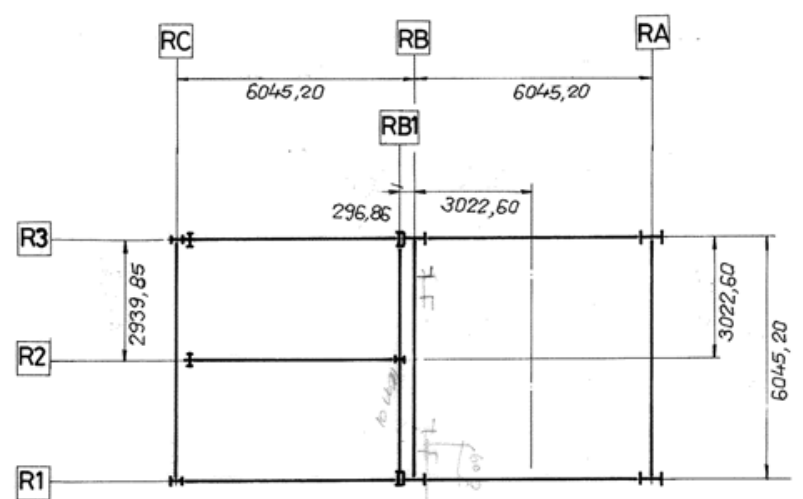

Fig. 5 - Structural axes diagram

The resistance steel structure, that supports the reactor, has a spatial composition and is a vertical truss type tower with two square cells from a top view, the two cells having a slightly different height regime. The main cell that supports the column of the reactor, $6,045 \times 6,045 \mathrm{~m}$ from a top view and an actual height of $36,27 \mathrm{~m}$, whereas the adjacent secondary cell, where the staircase, elevator and different landings are located, is of $6,045 \times 6 ., 45 \mathrm{~m}$ from a top view and an actual height of about $43 \mathrm{~m}$.

The resistance steel structure has a maximum height of approximately $47.3 \mathrm{~m}$ above the ground. The main levels are the following: $+4,461,+10,367,+16,272,+21,416,+27,321,+33,350$, $+36,541,+38,570,+44,115,+47,315$. The abutment elevation is approx. $+38,00$. At elevation 
$+3,540 \mathrm{~m}$, the steel structure is equipped with a rigid truss type system intended to stop the lateral strokes of the lower part of the riser.

The cell of the reactor has seven levels at different heights, delineated by technological platforms, whereas the secondary cell (the structure where the staircase and the elevator are located) has another two extra levels as compared to the main cell.

The braces are done with diagonals in "X", “", "“", depending on the technological requirements that in many places did not allow the disposition of two diagonals. The diagonals in " $X$ " are made of pairs of angle pieces with gussets and binding plates, whereas the simple diagonals are made of American profiles ("H").

All the beams are made of "I" or "H" profiles, with two soles and full core, mutual abutment and gripping, being done on the columns with bolted girders placed only on the cores of the beams (articulated clamp).

The resistance structure is made of OL37 (S235) steel.

\section{Subject and requirements of the design theme}

Currently, a new upgrading is wanted from a technological point of view by replacing the Reactor. The upper sections (the Reactor as such and the Striper) will be replaced with a higher capacity/ weight ones. The lower section - Riser - will remain unchanged.

Considering all these, there will consequently be an increase in mass and weight of 152.1 tons, respectively approx. $43 \%$.

\begin{tabular}{|l|l|l|}
\cline { 2 - 3 } \multicolumn{1}{c|}{} & $\begin{array}{l}\text { Mass } \\
\text { (tons) }\end{array}$ & Mass (tons) \\
\cline { 2 - 3 } \multicolumn{1}{c|}{} & Actual & Proposed \\
\hline Reactor + Striper & 282.9 & $\mathbf{4 3 5 . 0}$ \\
\hline Riser & 73.6 & $\mathbf{7 3 . 6}$ \\
\hline TOTAL & 356.5 & $\mathbf{5 0 8 . 6}$ \\
\hline
\end{tabular}

Compared to all the solutions proposed and analyzed in the previous years, this is the biggest increase in the capacity of the Reactor, with the greatest and most severe impact on the resistance structure that supports it.

Another constraint imposed by the Beneficiary was that the maximum strokes, from the abutment elevation of the Reactor, not to exceed $32 \mathrm{~cm}$ for seismic action - SLU.

The structure must be included in Class I of importance considering the highly dangerous content of the Reactor, as well as the outmost commercial importance that the operation of the refinery under normal parameters has.

Works on the foundations should be minimal and it had to be taken into account that works were possible only in their upper section.

The retrofitting of the structure must be carried out while the Reactor is in operation.

\section{Analysis of the existing structure with the proposed Reactor}

Seismic action:

Peak ground acceleration: $a_{g}=0,28 \mathrm{~g}$

Importance - exposure coefficient $\gamma_{1}=1.4$ 
Inelastic design spectrum:

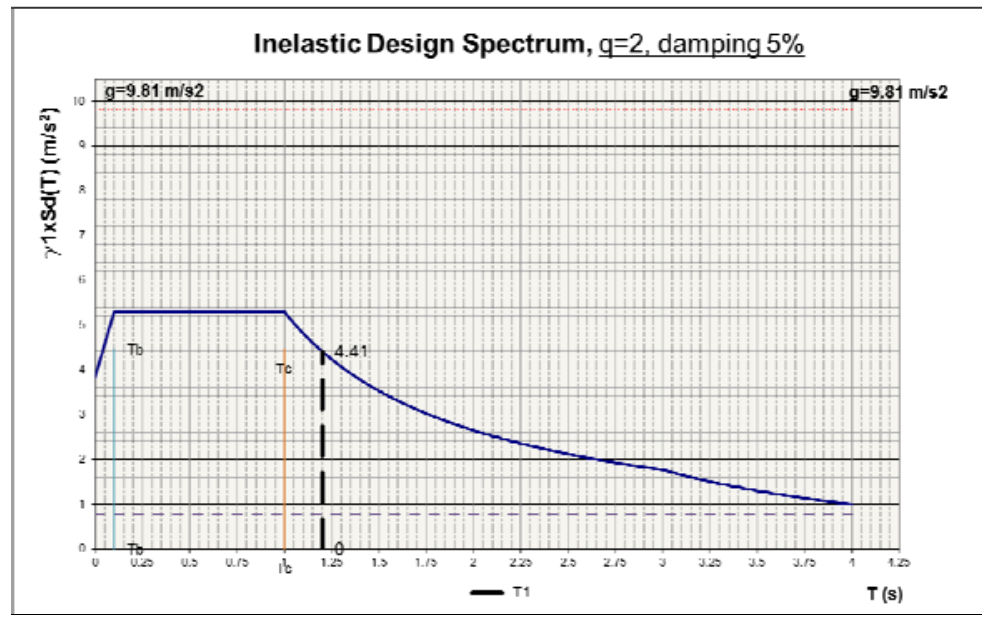

Fig. 6

For Ploiești: $\mathrm{TB}=0,1 \mathrm{~s}, \mathrm{TC}=1.0 \mathrm{~s}, \mathrm{TD}=3.0 \mathrm{~s}$

The construction has the behavior of an inverted pendulum, having approx. $80 \%$ of its mass amassed at its top. This is why the overall behavior factor, used in the elastic analyses based on the response spectra was: $q=2$.

The working load on the access and maintenance platforms: $0,70 \mathrm{kN} / \mathrm{m}^{2}$.

Technological loadings: according to the technological layouts and data received from the General Design Engineer. These loadings will not be presented in detail here because they have a complicated configuration and are not the subject of this article. As a magnitude reference, the total of these technological loadings amounts to $457 \mathrm{kN}$ (without including in this value also the partial safety coefficients).

The wind action was considered according to Conf. CR 1-1-1-4:2012.

The snow action, on the frontal structure can be neglected. It is an open truss type structure that does not allow and favor snow to amass, while the technological process involves a large emission of heat in the area of the Reactor which enables the melting of any snow fall.

The consolidation of the effects of the actions was carried out according to the Code of Design CRO - 2012 - Bases of Constructions Design.

The results of the modal analysis for the existing structure, with the newly proposed Reactor:

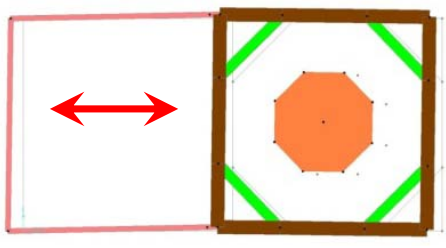

$\mathrm{T} 1=1.60, \mathrm{C} 1=83 \%$

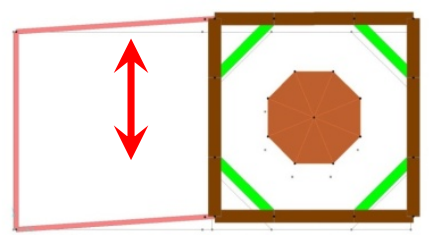

$\mathrm{T} 2=1.54, \mathrm{C} 2=81 \%$

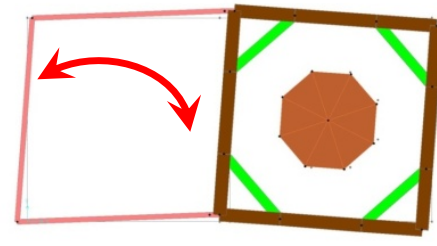

$\mathrm{T} 3=0.64$

\begin{tabular}{|l|c|c|}
\hline & Spectral analysis & FNA Analysis \\
\hline Basic shearing force: & $\mathbf{B S F}=\mathbf{2 3 0 4} \mathbf{~ k N}$ & $\mathbf{B S F}=\mathbf{2 2 7 1} \mathbf{~ k N}$ \\
\hline
\end{tabular}

The weight of the construction, in the sections that include seismic action: $G=6400 \mathrm{kN}$

The maximum horizontal displacement at the abutment elevation of the Reactor $(+36.27)$ : 
(since the displacements on both directions are comparable, those on the transversal direction - Y being nevertheless slightly higher, only the values for this transversal direction will be presented)

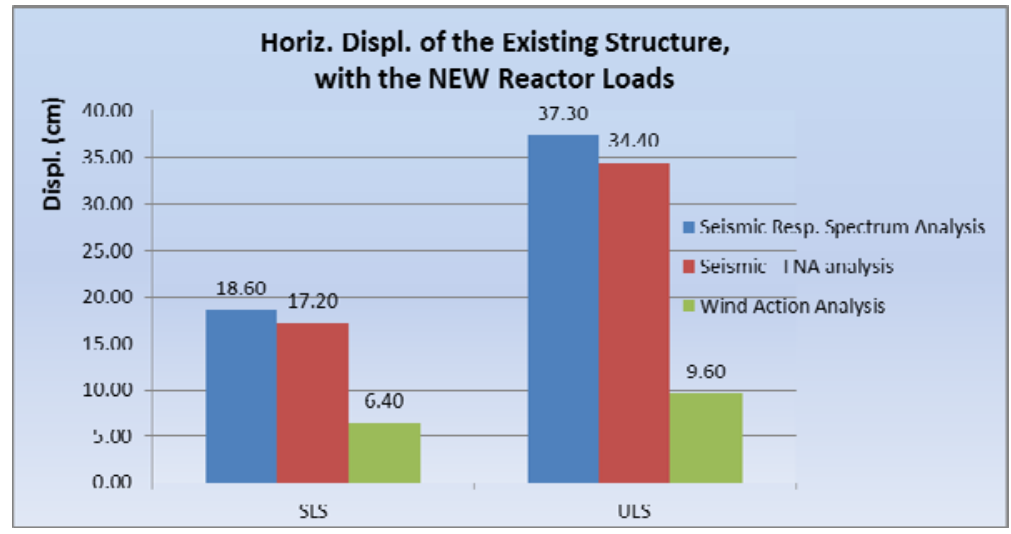

Fig. 7

Indicator R3 and seismic risk class resulted from assessment by calculation of the structure:

From spectral analyses: R3 $=0.38$. From nonlinear dynamic analysis: $\mathrm{R} 3=0.50$.

Consequently, the existing structure, with the proposed Reactor, is classified within Class II of seismic risk.

Regarding the existing foundation system:

The occurrence possibility of the rollover effect was verified, but this does not represent a hazard or a real problem, as the foundation is a common one for the Reactor, Regenerator and the Inlet Distillation Column. The real issue at the level of the foundations consists of the stresses that may occur in the foundation section between the structure of the Reactor and that of the Regenerator.

Following the evaluation of the resilience to bending of the foundation system, in the mentioned section, there resulted a capacity:

$$
M_{R d}^{+(\text {bottom })} \cong+78000_{-} k N m, M_{R d}^{-(\text {top })} \cong-70000_{-} k N m
$$

\section{Approach and calculation concept for establishing the retrofit solution}

\subsection{Analyzed aolutions and chosen solution}

Various solutions were analyzed, with different approach and calculation particularities. Some of the solutions studied cannot bring the structure to the safety parameters imposed by regulations.

In terms of energy, the system is characterized by the following equation:

$$
E_{I}=E_{k}+E_{s}+E_{h}+E_{d}
$$

Where

- $\quad E_{I}$ represents the input energy or the seismic energy

- $\quad E_{k}$ represents the kinetic energy of the structure (that can be neglected)

- $E_{s}$ represents the energy dissipated by elastic strain

- $\quad E_{h}$ represents the energy dissipated by hysteresis (plastic strain)

- $\quad E_{d}$ represents the energy dissipated by damping 
As a rule, for a given input energy, the response of the structure can conform through different approaches:

a) Either through enhancing the capacity of the structure through elastic strain

b) Either through enhancing the ductility of the structure and enhancing its elastic strain capacity

c) Either through enhancing the damping of the structure

Firstly, we will review the solutions analyzed, according to the above mentioned principles a) and b).

\section{Classical retrofit}

Through a classical retrofit, it was attempted to enhance the resistance capacity of the columns, beams and braces either by their replacement, or by adding welded steel sheets.

The behavior coefficient was considered $q=2$.

Practically, in the general equation of the energies equality, it is intervened by trying to increase the value of the Es member.

$$
E_{I}=E_{k}+E_{S}+E_{h}+E_{d}
$$

\section{Retrofit by using buckling resistant braces (BRB), thus by enhancing the ductility of the structure}

The principle of this retrofitting type is similar to the one of the classical retrofit (in regards to the retrofitting and replacement of the structural elements), with a major difference given by the fact that instead of the diagonals made of laminated profiles, these ones are replaced by buckling resistant diagonals, that create a highly ductile structure, characterized by a much higher behavior factor.

Practically, in the general equation of the energies equality, it is intervened by trying to increase the value of the Eh member.

$$
E_{I}=E_{k}+E_{s}+E_{h}+E_{d}
$$

Because within a single article, we cannot detail also the analyses or the results of the analyses for all the solutions studied, we will mention briefly that none of the above mentioned versions resulted in a solution to meet all the requirements, either from the point of view of the overall resistance and stability also at the level of the element, or from the point of view of technological constraints.

The results of the analyses through calculation, as well as the physical impossibility to carry out the retrofit of the columns up to an acceptable safety, resistance and stability level, led to the conclusion that a classical approach to upgrade the structure is not practically possible.

\section{Base isolation}

It was also considered to study and implement an insulation system for the base of the construction. Nevertheless, this solution was eliminated from the very beginning at the request of the Beneficiary because it would have been impossible to carry it out: at the level of the construction base there is a multitude of installations, equipment, pipes buried among the foundation beams, etc. Their presence makes it impossible to modify the foundation system to allow the installation of some base insulators.

\section{Enhancement of the structural damping}

The idea of this solution consists of turning the structure into a moment frame system at the same time with the introduction of a system to enhance the structural damping. 
The structural system becomes more flexible, the dynamic amplifications are nonetheless much smaller than with a truss type system, thus the seismic input and efforts in the structural elements decrease.

To achieve however a truly significant decrease of the efforts in the structural elements, it is needed to increase also the structural damping that is to limit also the lateral strokes of the system that became more flexible. This is achieved by using different seismic systems or devices. In this case, the most suitable are the viscous damper type elements mounted in the diagonals of the structure, thus the geometry of the structure and the technological routes remain unaltered.

Practically, in the general equation of the energies equality, it is intervened by trying to increase the value of the Ed member.

$$
E_{I}=E_{k}+E_{s}+E_{h}+E_{d}
$$

\section{Final structural retrofit solution}

\subsection{Brief description of the retrofitting solution}

The retrofitting solution involves:

- Creating horizontally some rigid diaphragm type elements (Fig. 10) that currently do not exist and that are to level the dispersion of the horizontal efforts towards the columns. These elements, as they may not be placed inside (because of the existence of the Reactor), will have to be positioned on the exterior of the structure, at every level of the main structural beams.

- Strengthening of the columns (Fig. 11, Fig. 12), by welding steel sheets 30-50 mm thick.

- Replacement of the existing beams with more rigid ones - IPE 600 (Fig. 13), connected with the reinforced columns by rigid joints / knots, beams that are to stabilize the columns to prevent their buckling, specific to the frameworks with adjustable knots.

- To create thus a moment - frame type structural system.

- The diagonals of the structure were kept in their initial positions, but they were replaced with others with a profile adapted according to the efforts that need to be overtaken as per the structural analyses (Tv 180x180x10)

- The new diagonals will not be continuous (from knot - to knot), but they will be intermittent. Viscous dampers will be mounted in the interruption area (along the diagonal) - Fig. 8 .

- Local works at the level of the foundations and securing devices of the steel columns in the foundations

- The additional mass mounted at elevation $+36,27$ will be dismounted and evacuated (together with the viscous - elastic dampers that connect this mass with the structure)

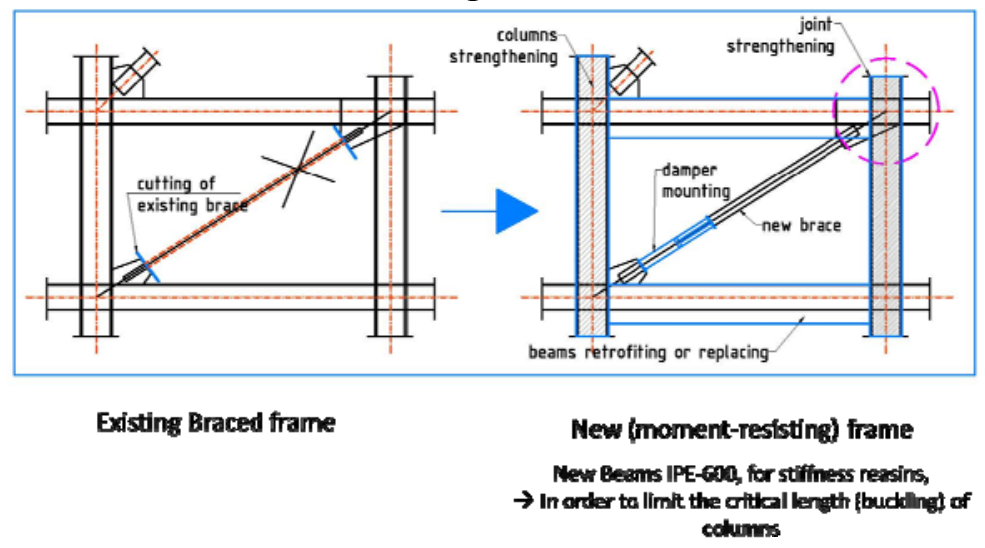

Fig. 8 - Diagram of the structure frame modification and retrofitting 


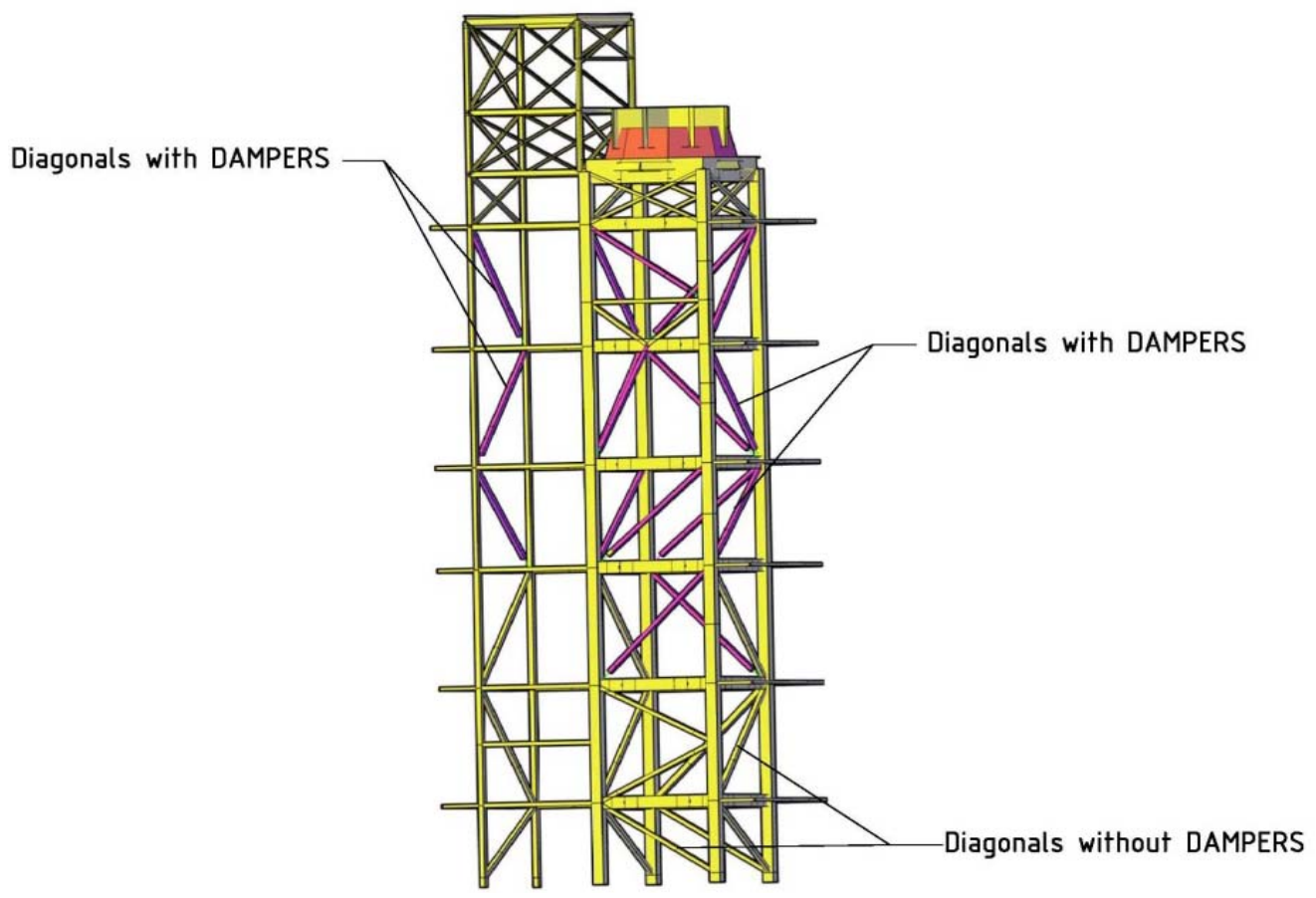

Fig. 9 - Diagram of modified and retrofitted structural system

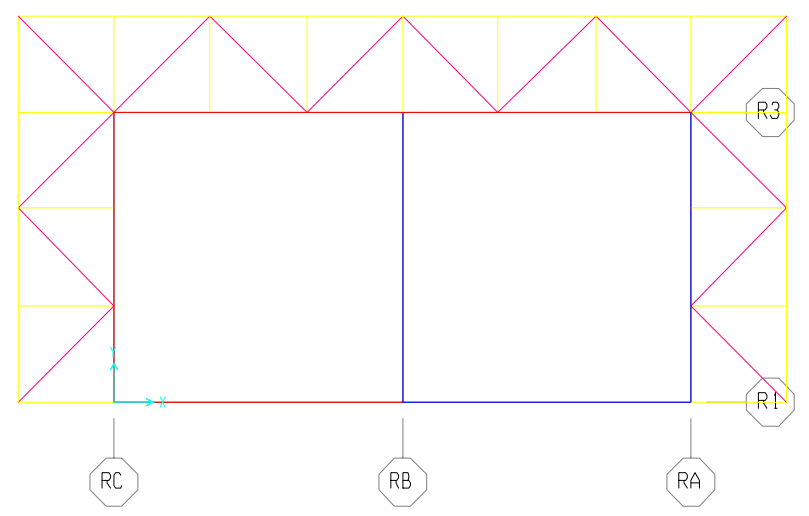

Fig. 10 - Introduction at each level of a truss type beam horizontally developed on the 3 free sides of the structure (axes RA, RC and R3) over a distance of $2 \mathrm{~m}$ outside the main structure

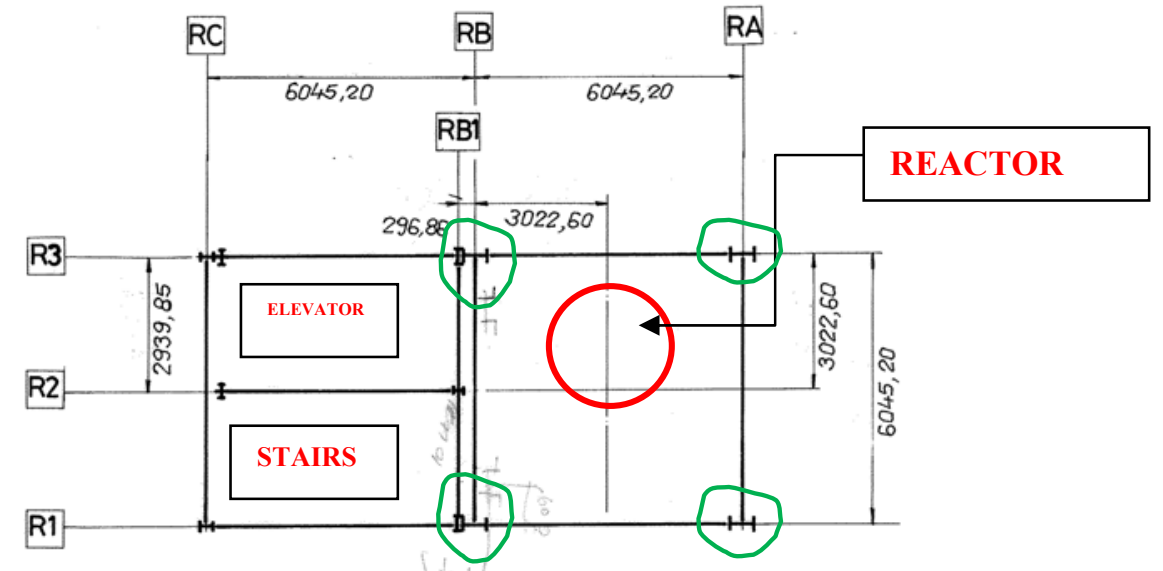

Fig. 11 - The columns of the Reactor cells that will be strengthened

NOTE: the columns of the staircase and elevation need also some reinforcements, but these ones have a much smaller amplitude and, in order to better highlight the major works, they are not pointed out in the figure above. 
The strengthening of the columns of the Reactor cell involves their interlocking by adding welded sheets (Fig. 12). The beams of the Reactor cells will be replaced beams with an IPE-600 profile or similar in rigidity and resistance (Fig. 13).

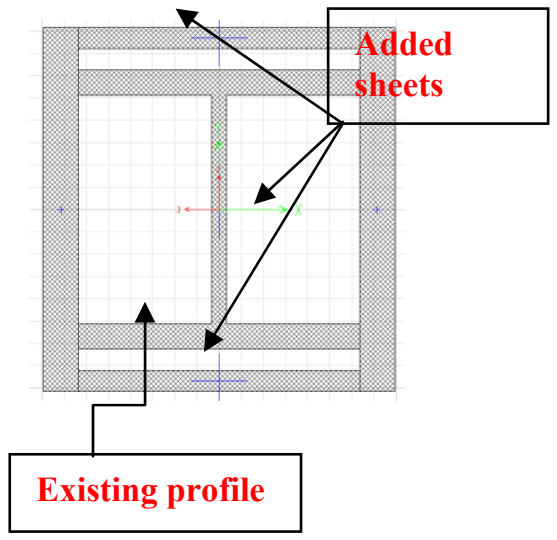

Fig. 12

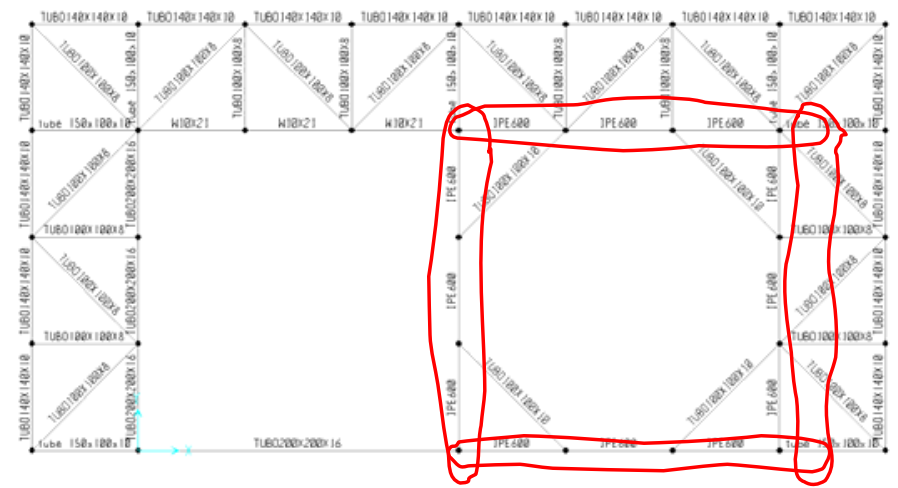

Fig. 13

After the columns are retrofitted in the nodes, the new beams are placed, together with the horizontal trusses (Fig. $14 \& 15$ )

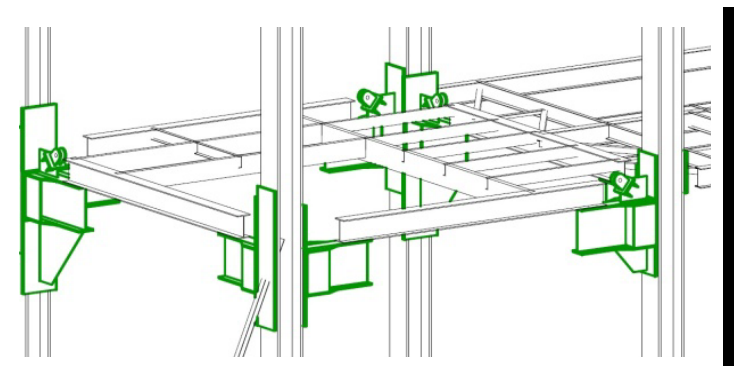

Fig. 14

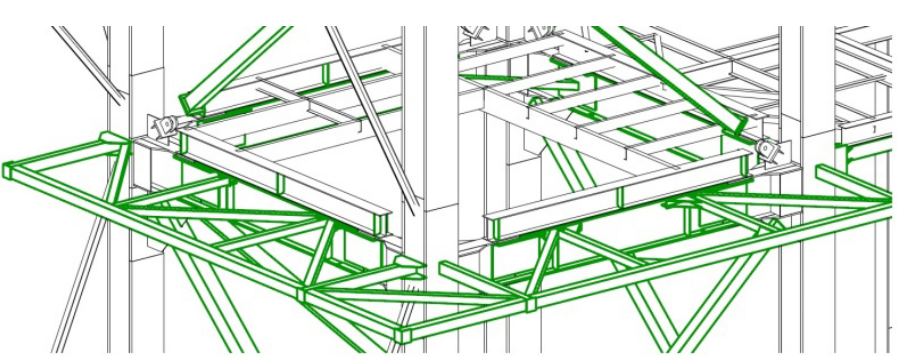

Fig. 15

The critical foundation section, between the Reactor and Regenerator, could be reinforced by adding carbon fiber strips at the top. (The critical load is the bending one through which the upper fiber of the foundation is stretched; for the opposite bending load - with the compressed upper fiber of the foundation.)

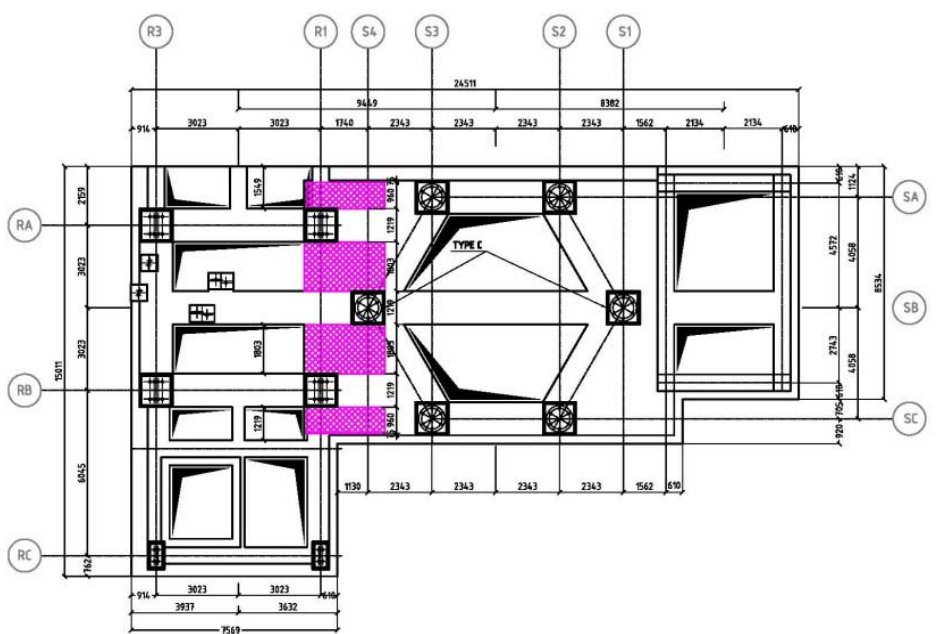

Fig. 16 - Adding carbon fiber strips at the top side of the foundation

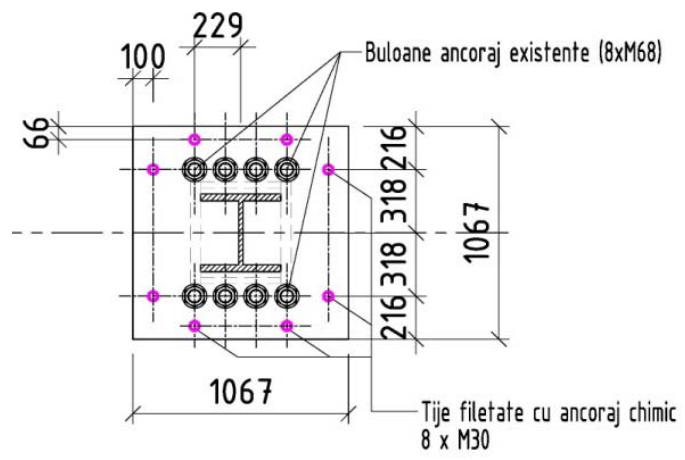

Fig. 17 - Supplementing the anchor bolts

All the knots, gussets, etc., modifications involved welding works on site. 
According to the regulations of Petrobrazi Refinery and the legislation in effect, for such industrial platforms, the fire protection of the structural elements is compulsory up to a height of min. $6 \mathrm{~m}$ or on two levels. For this reason, but also to ensure a sufficient rigidity at wind action, viscous dampers were not installed on the first two levels. For the first levels of the structure, the trusstype system was maintained, with "classical" diagonals, adjusted in the elastic behavior field.

\subsection{Working scenario and calculation stages}

The solution with viscous dampers enabled the reinforced structure to be verified in the elastic field. It was considered a behavior factor $q=1.5$ (elastic behavior) that involves ensuring that the remaining of the structural elements will not undergo any plastic strain or significant damage.

Introducing the additional viscous damping is an engineering problem with a high degree of difficulty.

The initial question is raised - "what is the necessary damping to satisfy the requirements?"

Stage I - spectral analysis with determining the target damping

Firstly, the spectral analyses were carried out, iteratively, using scaled response spectra for different values of the fraction from the critical damping, to determine the value triggering favorable results and establishing thus a target damping.

Comment: At the time of concluding the contract and the project design, the seismic code in effect was P100-1/2006.

After several iterations, it was determined that the damping target to meet the given requirements must be between $20 \%-25 \%$.

Comment: The target damping determined in the early stages of the project was set at $25 \%$, but over the course of the project, we were notified a series of additional loads, data and information that were implemented accordingly in the model. At the same time, as the analysis iterations were done, the gradual simulation of the reinforced sections of the steel structure was also carried out. In a final phase of the spectral analyses, the target value of the critical damping fraction was $20 \%$.

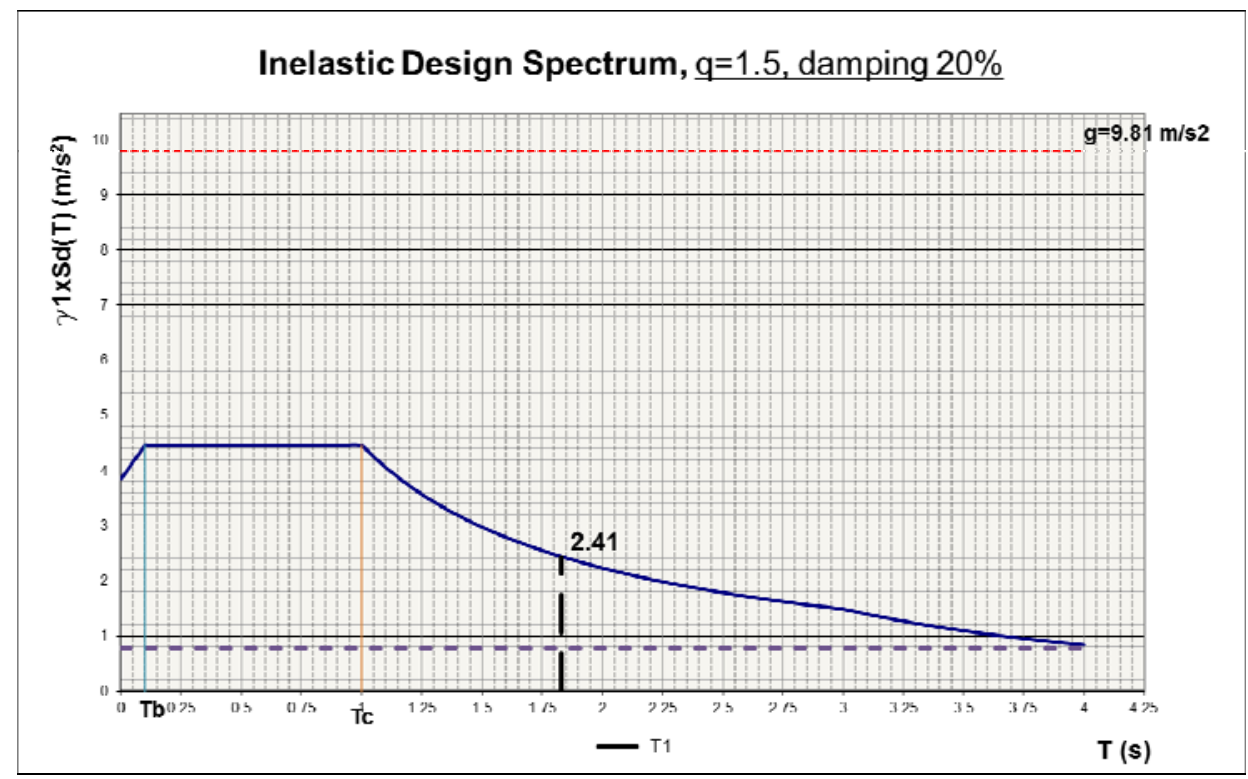

Fig. 18

NOTE: for the reinforced structure, the resulted fundamental periods of vibrations were: $\mathrm{T} 1=1.88 \mathrm{~s}, \mathrm{~T} 2=1.75 \mathrm{~s}$ 
STAGE II- Analysis of type nonlinear modal time history (FNA)

Subsequently, there was done the fine-tuning of the model and design as such of the sections in need of reinforcement, using at the same time both the spectral results of the analysis and the Modal Time History (also known as Fast Nonlinear Analysis - FNA) analysis type. At this stage, for the dynamic analyzes 3 sets of artificially generated accelerograms were used.

The positions of the dampers on the structure were established and the necessary damping constants were estimated according to the FEMA 356 methodology, after which the construction was loaded with input of the type accelerograms compatible with elastic site spectrum (for this case, the elastic spectrum with $2 \%$ elastic damping was used).

The force from the dampers is given by the equation $F=C \cdot v^{\alpha}$, where:

$\mathrm{C}$ represents the damping constant

$\mathrm{V}$ represents the relative speed between the heads of the damper,

$\alpha$ represents the damping exponent. In case $\alpha=1$ a linear damping is considered, whereas for $\alpha \neq 1$ a nonlinear damping is considered.

Based on the pre-sizing calculations, the values of the damping constant were established for linear dampers. Subsequently, this was converted in the value corresponding to the nonlinear dampers and was adjusted following several analysis steps.

It was considered a damping exponent $\boldsymbol{\alpha}$ used by the European producers: $\alpha=0.15$.

STAGE III- Analysis of type nonlinear time history - direct integration

Then, there followed the stage of model fine-tuning, of final detail checks, and of completing the dynamic analyzes with another 4 sets of artificial accelerograms, using thus, in the end, 7 sets of accelerograms. However, at this stage, there were performed also nonlinear dynamic analyses of direct-integration type (highly consuming of analysis time).

It was initially considered the structure designed and set up during stage II with the artificial input described above, after which the actual verification of the resistance structure was carried out in terms of strength and deformability checks.

Finally, after fine-tuning the calculations using the maximum of 7 synthetic accelerograms, the following parameters resulted for the viscous dampers:

\begin{tabular}{l|l}
\hline Longitudinal & Transversal \\
\hline 8 dampers, $\mathrm{C}=350\left[k N \cdot\left(\frac{s}{m}\right)^{\alpha}\right]$ & 9 dampers, $\mathrm{C}=350\left[k N \cdot\left(\frac{s}{m}\right)^{\alpha}\right]$
\end{tabular}

All the accelerograms were compatible with the elastic response spectrum, according to P100/1-2006:

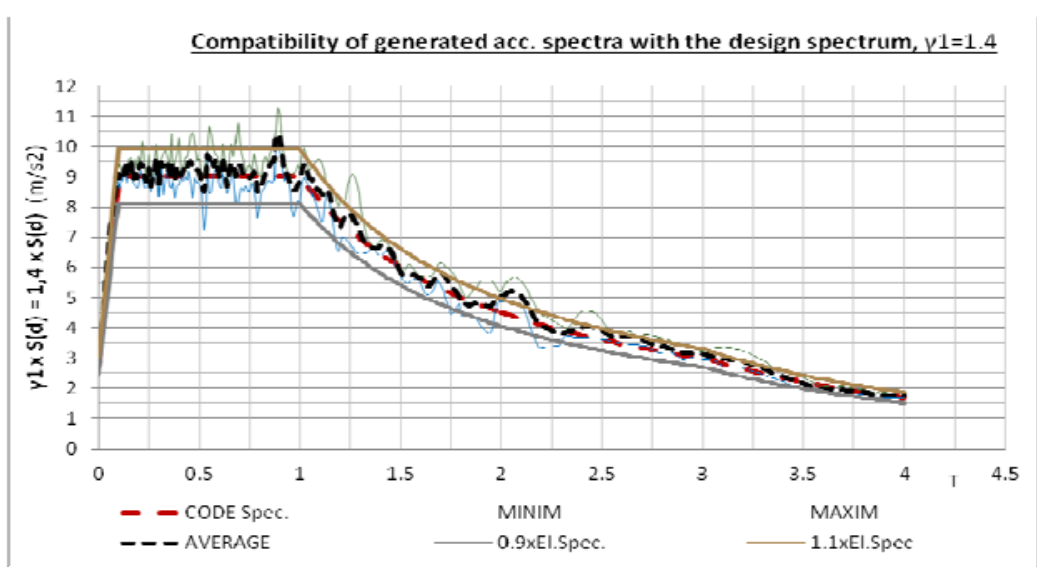

Fig. 19 - Classifying the average values of the generated accelerograms spectra within the 90\%-110\% ranges related to the elastic response spectrum 
STAGE IV-Verification of the overall damping in the structure

As a final verification and confirmation of the solution, the resulting overall damping in the structure was calculated.

$\xi_{d}=\frac{W_{D}}{2 \pi W_{s}}$ where $W_{D}$ and $W_{S}$ are represented in Figure 6-11:

Considering a system with "N" degree of dynamic variance, the fraction from the critical damping of the system can be defined as:

$$
\xi_{\text {ef }}=\xi_{0}+\xi_{d}
$$

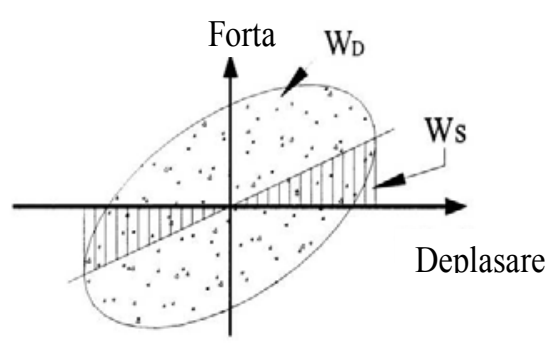

Fig. 20 - Defining the energy dissipated in an harmonic motion cycle - WD and the maximum energy of elastic strain - WS of a system with 1 GLD equipped with viscous damping device

where $\xi_{0}$ is the damping fraction of the NGLD system without dampers and $\xi_{d}$ is the damping fraction that devolves to the added dampers.

The added viscous damping resulted: $\quad \xi_{d}=\frac{W_{D}}{2 \pi W_{s}}=17 \%$

The total damping as fraction of the critical damping: $\quad \xi=2 \%+\xi_{D}=19 \%$

Comment: The target damping was of approx. $20 \%$ fraction from the critical damping and a value of approx. $19 \%$ was reached. This should not be nevertheless interpreted as an exact value, but as an indication of the overall damping level.

\subsection{Some results of the structural analysis}

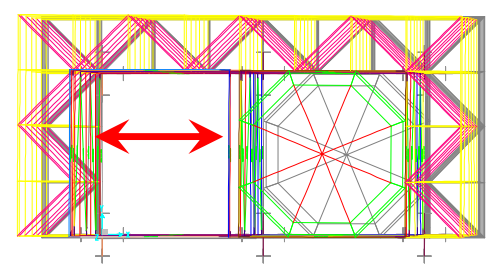

$\mathrm{T} 1=1.88, \mathrm{C} 1=84 \%$

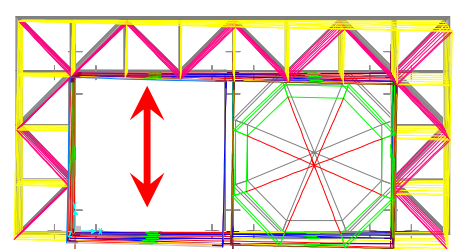

$\mathrm{T} 2=1.75, \mathrm{C} 2=81 \%$

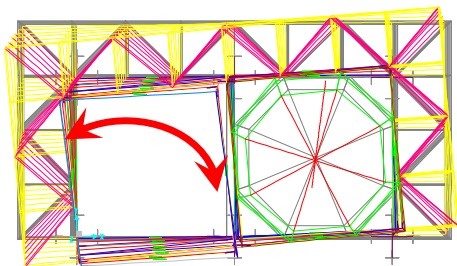

$\mathrm{T} 3=0.74$

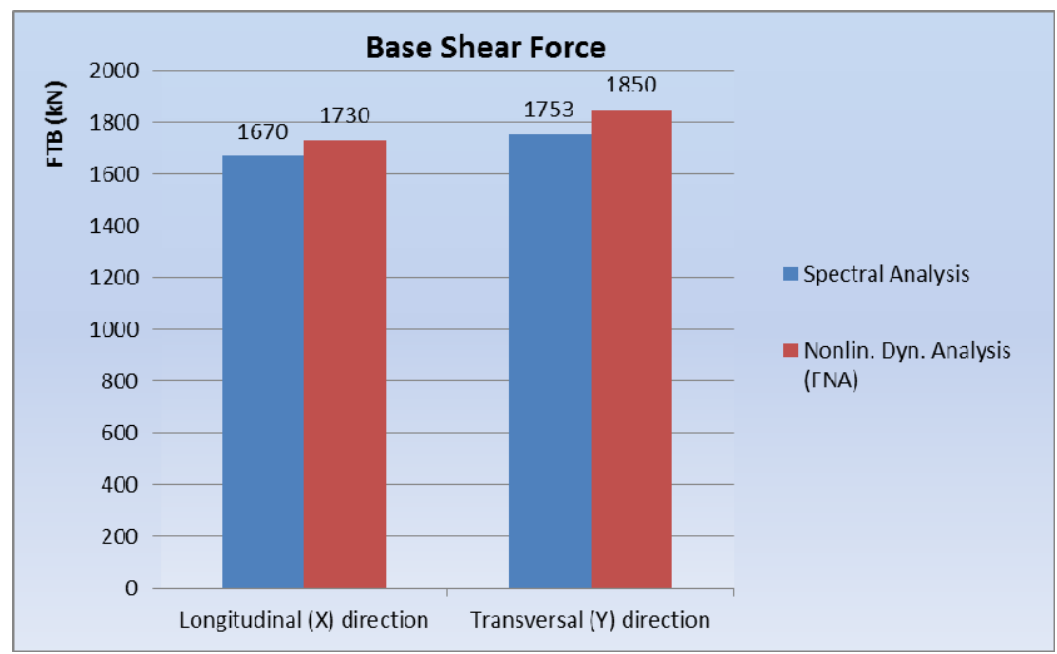


Following the retrofit works, the weight of the construction modifies - as compared to the actual status on site - as follows:

\begin{tabular}{|l|c|c|c|}
\hline & $\begin{array}{c}\text { Existing structure, with } \\
\text { existing reactor }\end{array}$ & $\begin{array}{c}\text { Retrofitted structure, } \\
\text { with new reactor }\end{array}$ & Increase \\
\hline Reactor weight & $3565 \mathrm{kN}$ & $5086 \mathrm{kN}$ & $43 \%$ \\
\hline Structure weight & $1160 \mathrm{kN}$ & $2670 \mathrm{kN}$ & $130 \%$ \\
\hline $\begin{array}{l}\text { TOTAL Reactor + Structure } \\
\text { (without considering the partial safety } \\
\text { coefficients, nor the other gravitational } \\
\text { loads) }\end{array}$ & $4725 \mathrm{kN}$ & $64 \%$ & \\
\hline $\begin{array}{l}\text { Total weight in the fundamental } \\
\text { combination }\end{array}$ & $5341 \mathrm{kN}$ & $9395 \mathrm{kN}$ & $76 \%$ \\
\hline $\begin{array}{l}\text { Total weight in the combinations that } \\
\text { include the seismic action }\end{array}$ & $4885 \mathrm{kN}$ & $8298 \mathrm{kN}$ & $70 \%$ \\
\hline
\end{tabular}

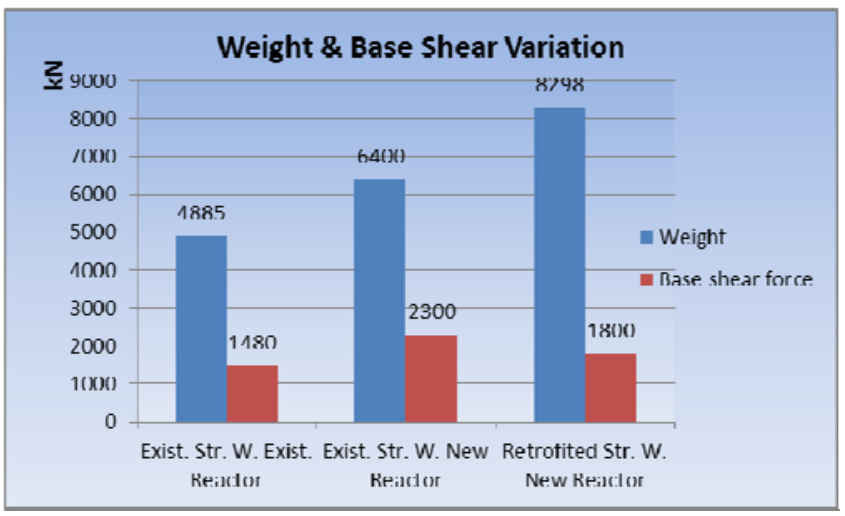

Fig. 21

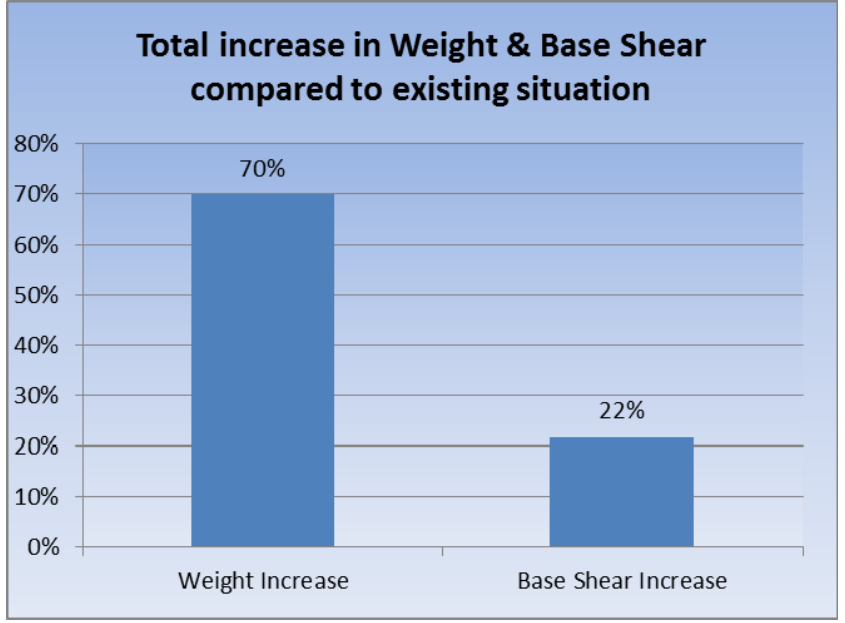

Fig. 22

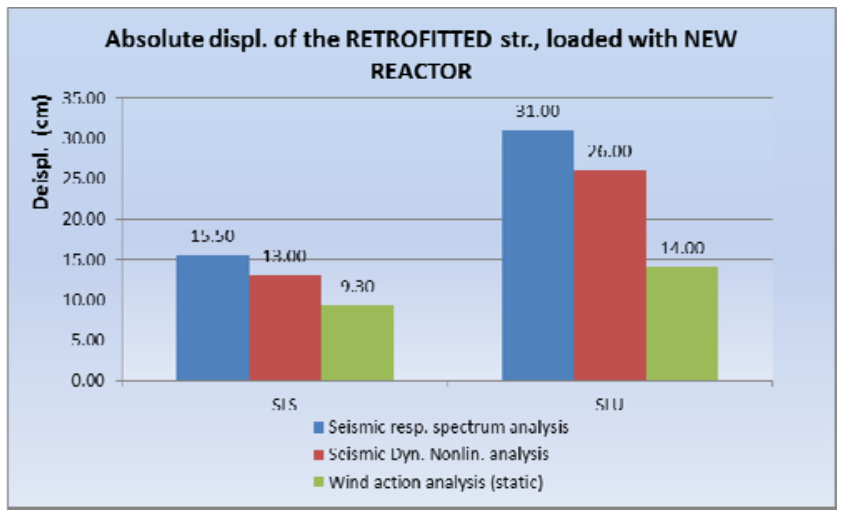

Fig. 23 


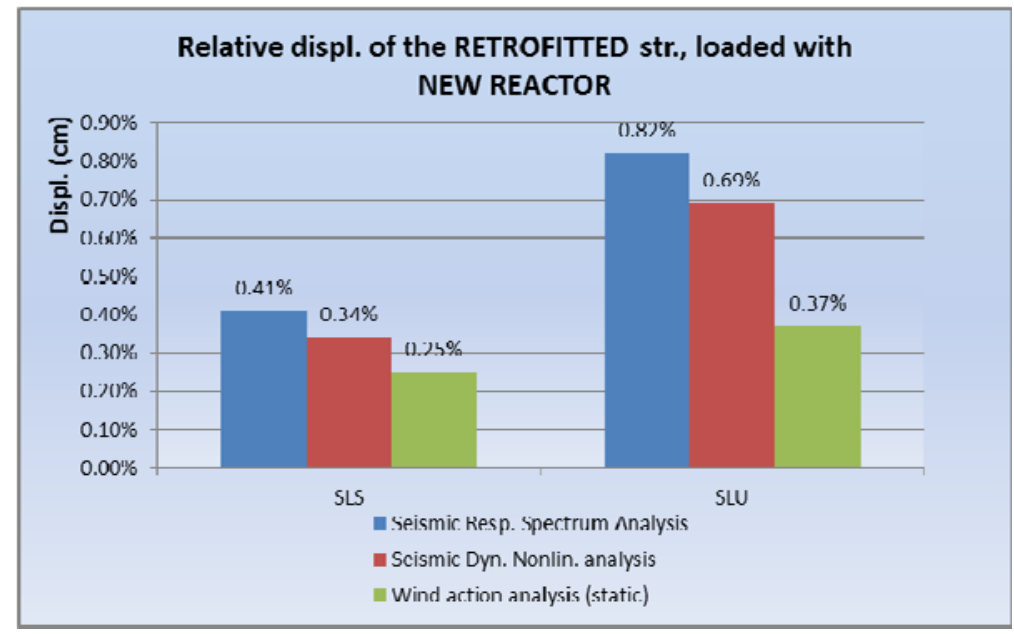

Fig. 24

Behavior of viscous dampers (example for 1 damper):

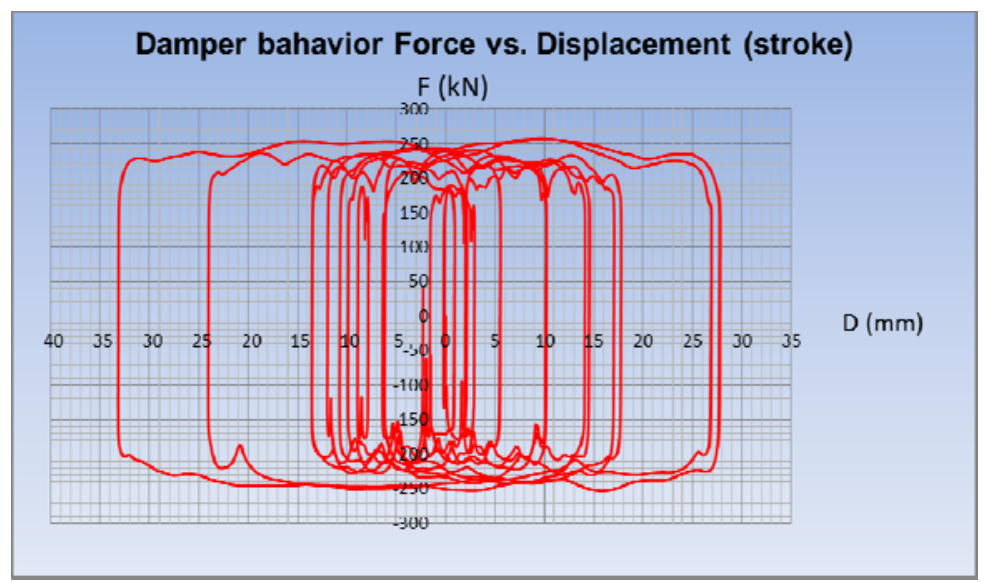

Fig. 25

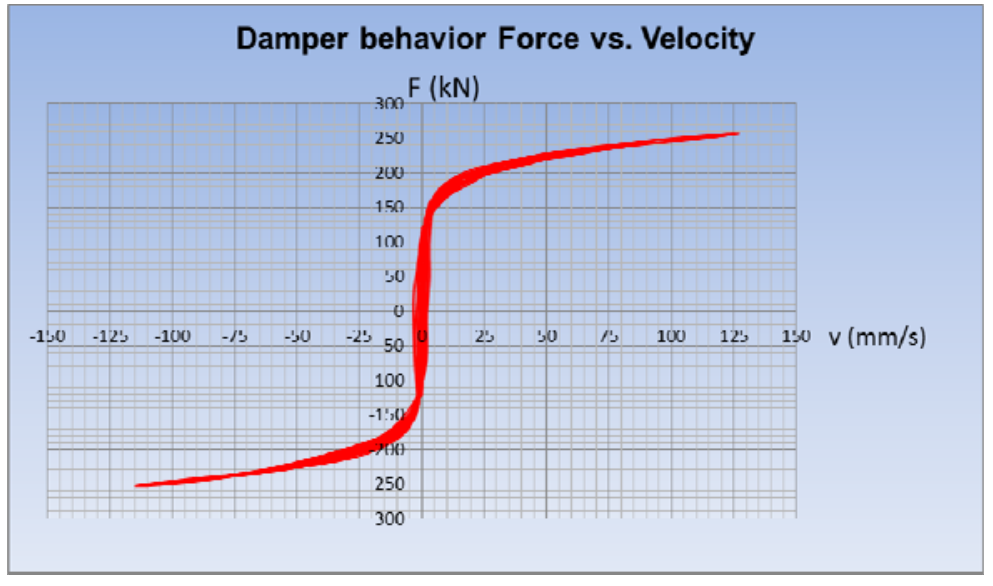

Fig. 26

A total of 17 viscous dampers were positioned ( 8 on the longitudinal direction and 9 on the transversal direction).

The following parameters resulted for the dampers (it was a considered a speed exponent $\alpha=0,15)$ :

Maximum force: $F_{\max }^{\text {design }}=275 \mathrm{kN}$; damper stroke $\mathrm{s}= \pm 50 \mathrm{~mm}$;

Maximum speed: $v_{\max }^{\text {design }}=0.197 \mathrm{~m} / \mathrm{s}$; damping constant $\mathrm{C}=350 \mathrm{kN}(\mathrm{s} / \mathrm{m})^{0,15}$ 


\section{Some details from the project}
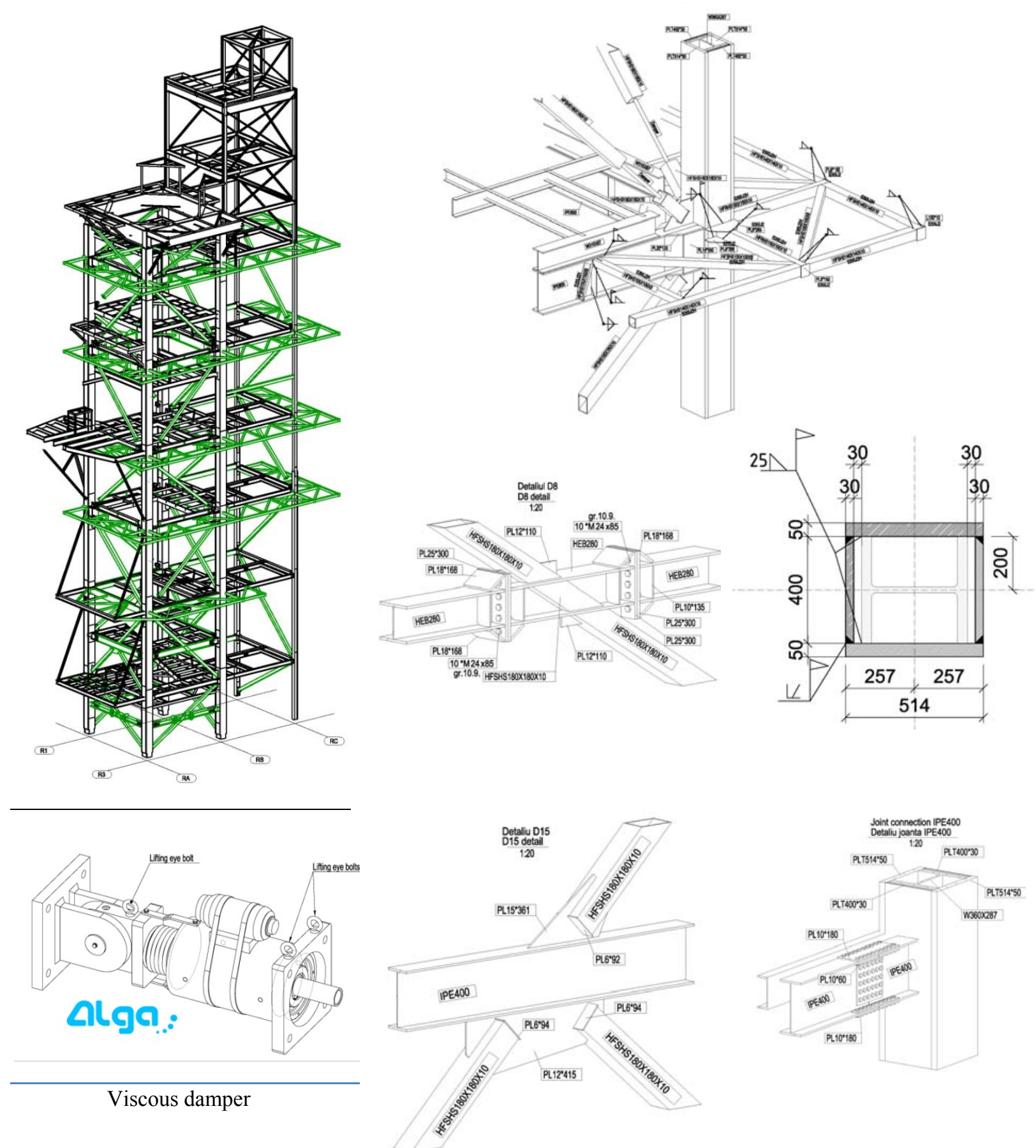

Viscous damper

\section{Ongoing research themes}

At the same time with the analyses corresponding to the seismic situation, linear static analyses were also carried out for equivalent static wind loads. Being a linear static calculation, it was not possible to consider the dampers and it was not possible to quantify their actual contribution also in case of wind action. Actually, the resistance checks and the strokes caused by the wind were not carried out on the structure considered as moment - frame system without dampers.

The aspects related to the effect of the viscous dampers to limit the lateral dflections triggered by the wind action as a dynamic action, were also also studied, within a comprehensive research process conducted by our office, in collaboration and with the support of a consultancy team 
made of Prof. Dr. Federico Perotti and Prof. Asist. Dr. Luca Martinelli, from Milano Polytechnics - Department of Static, Dynamic and Structural Theory. We would like to thank them on this occasion for their involvement in the project and the support granted. The results of this study will be presented in a future paper.

\section{Conclusions}

The resistance structure supporting the Reactor was verified taking into account the additional weight resulted from its modification, different solutions to retrofit the structure were considered so that the increase in gravitational loads can be absorbed by the structure, and especially to ensure a sufficient safety level to seismic actions for the Reactor supporting structure. By "sufficient", it should be understood "at least in line with the level of performance required by the regulations in effect, as a minimal threshold".

There was assessed the impact that the proposed changes will have on this structure, the degree of insurance to the seismic risk of the structure that will be loaded with the forces disseminated by the new reactor (modified), but also the behavior of the structure under the wind action.

In terms of approach, given the particular importance of the objective, as well as the requirements of the Beneficiary to obtain - through retrofit measures - a construction with a lifespan of 50 years (as new construction), it was considered imperative that the retrofit solution to get the classification of the construction into the seismic risk class IV, with an indicator $R 3 \geq 1$.

There were analyzed various methods and solutions for intervention and seismic rehabilitation. Subsequently, the analyses showed that the only possible solution (from both theoretical and practical point of view) for upgrading and retrofitting the structure was to enhance its damping (by introducing viscous dampers), along with the partial transformation of the structural system from a "truss-type"/ braced one into a moment frame one. At the same time, the columns of the structure will be reinforced by adding steel sheets, whereas the beams will either be strengthened in a similar manner, or be replaced with new ones, much more rigid so as to ensure the stability of the frame.

An overall damping (fraction of critical damping) of approximately $20 \%$ was targeted and a value of approx. $19 \%$ was achieved.

The steel structure was dimensioned for a quasi-elastic behavior field $(q=1.5)$.

The solution triggers highly positive benefits, not only in terms of the retrofit possibility on site, but also in terms of the effect on existing foundations where the intervention possibilities were extremely limited. At the level of the foundations, an intervention with a low difficulty in practical terms was carried out.

The retrofit works were completed at the end of 2014.

\section{References}

[1]. Bețea S., Vezeanu. (2009). Alternative solutions for steel structures with centric bracing. 4th National Conference for Seismic Engineering

[2]. Crăifăleanu I.G. (2005). Nonlinear models with a variance degree in seismic engineering.

[3]. Hwang J.S. Seismic Design of Structures with Viscous Dampers (2002). International Training Programs for Seismic Design of Building Structures.

[4]. FEMA 356. Prestandard and Commentary for the Seismic Rehabilitation Of Buildings (2000).

[5]. FEMA 273. NHERP Guidelines for Seismic Rehabilitation of Buildings (1997)

[6]. Trevor E. Kelly - Holmes Design Group. In-Structure Damping and Energy Dissipation (2001). www.holmesgroup.com

[7]. Marcu D. (2001). The active response of the structures to the dynamic actions by using the dampers with additional mass. 